\title{
Model of the solutes transfer during osmotic dehydration of vegetal matrices: a proposal
}

\section{Muñiz, S. ${ }^{a^{*}}$; Méndez, L. ${ }^{\text {; }}$ Rodríguez, J. ${ }^{\text {a }}$ Sandoval, S. ${ }^{\text {a }}$}

a. Instituto Politécnico Nacional, Centro Interdisciplinario de Investigación para el Desarrollo Integral Regional Unidad Oaxaca, Calle Hornos 1003, Santa Cruz Xoxocotlán Oaxaca, CP 71230, México.

*E-mail of the corresponding author: sahylin85@gmail.com

\begin{abstract}
Osmotic dehydration of apple was modeled considering the mechanisms involved in the solutes transfer within the plant matrix: impregnation and diffusion. The model mathematical writing includes the impregnation layer thickness, the diffusion thickness, a water bulk flow and the convective resistance. Apple cylinders were dehydrated at 30, $50^{\circ} \mathrm{C}$ and $30,50^{\circ} \mathrm{Brix}$ and a motion of $0.15 \mathrm{~m} / \mathrm{s}$. The Reynolds number was of 250 for $30^{\circ} \mathrm{C}-30^{\circ} \mathrm{Bx}$ and 500 for $50^{\circ} \mathrm{C}-50^{\circ} \mathrm{Bx}$. Schmidt numbers was of 4000 for $30^{\circ} \mathrm{C}-30^{\circ} \mathrm{Bx}$ and 4200 for $50^{\circ} \mathrm{C}-50^{\circ} \mathrm{Bx}$.
\end{abstract}

Keywords: transfer; solute; impregnation; osmotic dehydration. 


\section{Introduction}

The understanding of the mechanisms involved in the solutes transfer within the food is fundamental to develop a predictive model of the osmotic dehydration operation. The mechanisms present in the solute transport of the osmotic solution within the plant tissue have not been elucidated. The solute transfer models developed so far, describe the osmotic solution migration by calculating a global transfer coefficient that considers a gradient of solute concentration uniform inside the food, limiting the identification of the mechanisms involved: diffusion or impregnation (Muñiz and others, 2017).

These models apply Crank's solutions to Fick's law to determine the transfer coefficient and they suppose some simplifications that contradict experimental findings that show the presence of solutes concentrated layers on the material surface, particularly when saccharides and sweeteners are used as osmotic solutions, which are evidence of an unequal distribution of osmotic solution within the plant matrix (Assis and others, 2015; Seguí and others, 2012).

Unlike the models available in the literature that consider a global solute transfer coefficient, this work proposes a model that describes the mechanisms involved in the transfer of the solute within the plant matrix: impregnation and diffusion and assumes boundary conditions that they take in counts the effect of external and internal resistances in the fruit-osmotic solution interface.

\section{Materials and Methods}

\subsection{Boundary conditions for the modeling of solute transfer in osmotic dehydration.}

Apples samples were considered as slab and solute transported was assumed to occur in one direction. For boundary conditions the overall solute transfer process depend of the relationship of internal and external resistances in the osmotic solution-apple interface, determined by Reynolds and Schmidt numbers.

\subsection{Movement velocity and dimensionless numbers.}

Apple samples were moved in a vertical in a vertical direction at frequencie of 100 cycles/minutes about $0.15 \mathrm{~m} / \mathrm{s}$.

Solution movement was affected significantly by solute movement, therefore the interface resistance was not negligible. Thus at the solution-apple interface the boundary conditions is: 


$$
K\left(C_{\infty}-C_{s}\right)=-D_{s}\left(\frac{\partial C}{\partial x}\right)_{s}
$$

K-mass transfer coefficient $(\mathrm{m} / \mathrm{s})$, $\mathrm{C}_{\infty}$ - solution concentration far from the interface $\left(\mathrm{kg} / \mathrm{m}^{3}\right)$ and $\mathrm{C}_{\mathrm{S}}$-solution concentration at the interface apple-osmotic solution $\left(\mathrm{kg} / \mathrm{m}^{3}\right)$.

The velocity was determined by the equation (2):

$$
U=\frac{2 \pi R w}{\cos \left(2 \pi w t_{m}\right)}
$$

U-verticalvelocity $(\mathrm{m} / \mathrm{s}), \omega$-frequency (cycles/minutes), R- radius $(0.015 \mathrm{~m})$ and $\mathrm{t}_{\mathrm{m}}$-time of the movement (s).

The relative velocity of apple sample and solution was supposed to be the average velocity of apple. This velocity was used for calculation of Reynolds (Re) and Schmidt (Sc) numbers.

$$
\begin{gathered}
R e=\frac{L U \rho_{s}}{\mu} \\
S c=\frac{\mu}{\rho_{s} D}
\end{gathered}
$$

L-diameter of apple sample $(\mathrm{m}), \rho_{\mathrm{s}}$-solution density $\left(\mathrm{kg} / \mathrm{m}^{3}\right), \mu$-viscosity of the sucrose solution $(\mathrm{kg} / \mathrm{ms})$, D-binary diffusivity $\left(\mathrm{m}^{2} / \mathrm{s}\right)$. Sucrose solution viscosity and density were estimated from the literature.

\subsection{Penetration depth of the solute or active zone.}

The penetration depth of the solute $\left(z_{p}\right)$ was determined experimentally using the scanning electron microscopy (SEM) technique. The apple sample was analyzed in cross section from the surface to the center. The thickness of the area where structural changes are observed was determined and used to estimate the penetration depth of the solute or active zone. In addition, the tissue area beyond the zone of structural change was observed to check if it remained as at the beginning of the treatment.

Prior to SEM examination, the materials were osmotically dehydrated by applying a factorial experimental design at two levels for temperature $\left(30,50^{\circ} \mathrm{C}\right)$, a sucrose osmotic solution concentration $\left(30,50{ }^{\circ} \mathrm{Bx}\right.$ ) and a motion level of $0.15 \mathrm{~m} / \mathrm{s}$. Three replicates for each treatment were conducted. High-quality stereo images and surface parameters were recorded from samples osmotically dehydrated and cut in cross section. For the study by SEM, the cross section of the apple sample was analyzed dividing it into 5 areas from the 
outermost layer to the center. Area 1 corresponds to the outermost surface of the sample and area 5 to the material center.

\subsection{Modelling of transport mechanisms during osmotic dehydration of fruit in sucrose solution.}

Modifying the mathematical writing of the equations that describe the solutes transport in OD requires an analysis of the mechanisms involved: impregnation and diffusion. For this it is necessary to take into account the following considerations: water bulk flow acts as a resistance that opposes the transfer of the solute and limits it to migrate mostly in the superficial layers of the food; the water flow from food is greater than the flow of solutes entering the plant matrix; water flow is the sum of: water in the pores (free water) + water in the extracellular volume + water in the intracellular volume (bound water); water that leaves the plant matrix is transferred mainly by capillary diffusion; solute flow is the sum of: solute in the pores + solute in the extracellular volume concentration of the osmotic solution inside the food changes; the highest concentration of the solute is impregnated on the surface of the plant matrix when solutions of saccharides and natural sweeteners are used; hydrodynamic boundary layer influences the initial concentration of the impregnation layer $\mathrm{C}_{\mathrm{i}}$; thickness of the impregnation layer $\delta_{\mathrm{imp}}$ changes with the time of the process. Based on the above assumptions, the following equations are proposed to determine the transfer of solutes in OD:

$$
\begin{gathered}
\frac{\partial C}{\partial t}=\text { solute flow potential }- \text { water flow potential } \\
\qquad \frac{\partial C}{\partial t}=\nabla^{2} C s-\nabla^{2} C w
\end{gathered}
$$

$$
\frac{\partial C}{\partial t}=\gamma(\text { Diffusion })-\gamma(\text { Capillary diffusion })
$$

$\nabla^{2} \mathrm{Cs}$-solute flow potential; $\nabla^{2} \mathrm{Cw}$-water flow potential; C-concentration $\left(\mathrm{kmol} / \mathrm{m}^{3}\right)$, ttime (s), $\gamma$-coefficient.

\section{Results and discussions}

Reynolds number (Table 1) for the experiment was found to be approximately 205 and 500 for $30^{\circ} \mathrm{C}-30^{\circ} \mathrm{Bx}$ and $50^{\circ} \mathrm{C}-50^{\circ} \mathrm{Bx}$ respectively with $0.15 \mathrm{~m} / \mathrm{s}$ of motion level. The flow regime for both experience were thus laminar flow. The calculation of dimensioanles 
numbers showed the average Reynolds number of all the experiments was small $(<600)$ and very high Schmidt numbers (4000 for $30^{\circ} \mathrm{C}-30^{\circ} \mathrm{Bx}$ and 4200 for $50^{\circ} \mathrm{C}-50^{\circ} \mathrm{Bx}$ ).

Table 1. Properties of the osmotic solution to determine the Reynolds number

\begin{tabular}{cccccc}
$\begin{array}{c}\text { Temperature } \\
\left({ }^{\circ} \mathbf{C}\right)\end{array}$ & $\begin{array}{c}\text { Concentration } \\
\left({ }^{\circ} \mathbf{B x}\right)\end{array}$ & $\begin{array}{c}\text { Diameter } \\
(\mathbf{m})\end{array}$ & $\begin{array}{c}\text { Velocity } \\
(\mathbf{m} / \mathbf{s})\end{array}$ & $\boldsymbol{R e}$ & $\boldsymbol{S} \boldsymbol{c}$ \\
\hline 30 & 30 & 0.015 & 0.10 & 250 & 4000 \\
50 & 50 & 0.015 & 0.10 & 500 & 4200 \\
\hline
\end{tabular}

During osmotic fruit dehydration, sucrose or synthetic osmotic solutions are generally used, in a mass fraction of $60 \% \mathrm{w} / \mathrm{w}$ or more. These solutions have high viscosity and have low diffusion. These operating conditions imply high Sc numbers and low Re numbers, generally in laminar flow regime (Bui and others, 2009).

From the thickness of the zone where the structural change was observed, the value of the penetration depth of the solute $z_{p}$ was estimated. Scanning electron microscopy turned out to be an efficient technique (Figures 1 and 2) for the detection of structural changes areas in the osmotically dehydrated apple tissue.
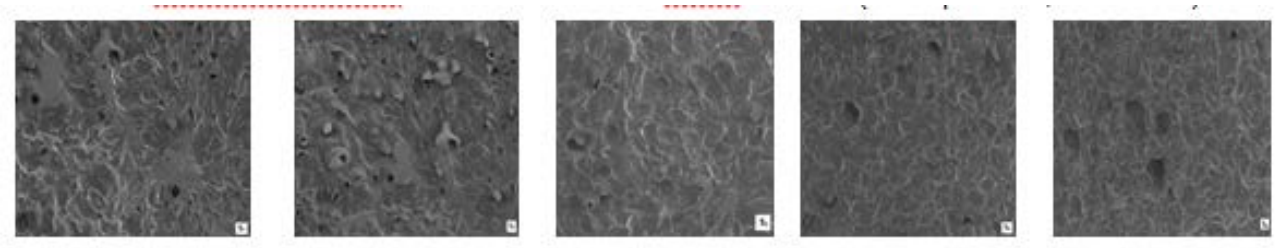

Fig. 1. Micrograph of dehydrated apple in sucrose $50^{\circ} \mathrm{C}-50^{\circ} \mathrm{Bx}$. Increase $50 x$ (S1-surface; S5center).
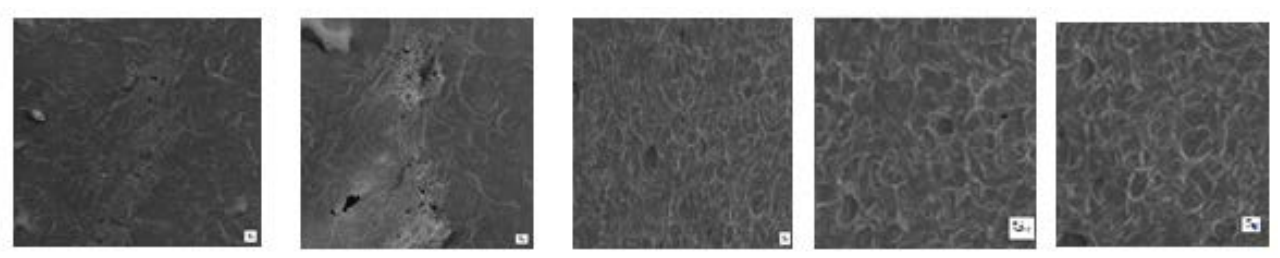

Fig. 2. Micrograph of dehydrated apple in sucrose $30^{\circ} \mathrm{C}-30^{\circ} \mathrm{Bx}$. Increase 50x (S1-surface; S5center).

In 1 and 2 areas the greatest structural changes are observed, these being the closest to the external surface of the material. In these areas, we observed certain zones where the structure of the tissue is collapsed with the presence of solids that clog the pores and the intercellular spaces disappear. In areas 3, 4 and 5 closest to the center of the sample, small and irregularly shaped intercellular spaces are observed, very similar to those presented in 
the microscopy of the fresh apple. The values of the solute penetration depth estimated were 3.03 and $3.68 \mathrm{~mm}$ for the conditions of $30^{\circ} \mathrm{C}-30{ }^{\circ} \mathrm{Bx}$ and $50^{\circ} \mathrm{C}-50{ }^{\circ} \mathrm{Bx}$.

\section{Conclusions}

This model can be useful for the design and optimization of the industrial osmotic dehydration process since it will be able to successfully predict the area where the superficial impregnation of the sucrose occurs and the area where the solute diffuses.

\section{References}

[1] Muñiz, S.; Méndez, L.; Rodríguez, J. Solute transfer in osmotic dehydration of vegetable food: a review. Journal of food science 2017, 82(10):2251-2259.

[2] Assis, F., Morais, R., Morais, A. Mass transfer in osmotic dehydration of food products: comparison between mathematical models. Food Engineering Reviews 2015, 8(2):116-133.

[3] Seguí, L.; Fito, P.; Fito, P. Understanding osmotic dehydration of tissue structured foods by means of a cellular approach. Journal of Food Engineering 2012, 110(2).

[4] Bui, H.; Makhlouf, J.; Ratti, C. Osmotic dehydration of tomato in sucrose solutions: Fick's law classical modeling. Journal of food Science 2009, 74(5). 